\title{
Regulation of ENT1 Expression and ENT1-Dependent Nucleoside Transport by c-Jun N-terminal Kinase
}

\author{
Andrea V. Leisewitz ${ }^{*}$ Eric I. Zimmerman ${ }^{*}$ Min Huang ${ }^{\dagger}$, Shannon Z. Jones ${ }^{*}$, Jing Yang ${ }^{*}$, and \\ Lee M. Graves ${ }^{*}$ \\ "Department of Pharmacology, School of Medicine, University of North Carolina at Chapel Hill, \\ North Carolina 27599-7365, USA \\ tDepartment of Medicine, Division of Oncology, Stanford University, Stanford, CA 94305-5796, \\ USA
}

\begin{abstract}
Equilibrative Nucleoside Transporters (ENTs) are facilitative transporters broadly selective for pyrimidine and purine nucleosides and are essential for the modulation of nucleoside concentration and nucleoside analog availability. Resistance to nucleoside-derived drugs strongly correlates with a deficiency of ENT1 expression in several tumor cells. Thus, it is crucial to understand the mechanisms by which this transporter is modulated. Using a mouse myeloid leukemic cell line as a model, we investigated whether stress-activated kinases regulate ENT1 expression and function. JNK activation, but not $\mathrm{p} 38$ MAPK results in rapid loss of mENT1 function, mRNA expression and promoter activity. c-Jun but not the mutant c-Jun Ser63/73Ala, decreased mENT1 promoter activity. Moreover cJun bound to an AP-1 site identified at -1196 of the promoter, suggesting a specific role for this transcription factor in mENT1 regulation. We propose that activation of JNK-cJun pathway negatively regulates mENT1 and suggest that this mechanism might contribute to the development of nucleoside analog-derived drug resistance.
\end{abstract}

\section{Keywords}

Equilibrative Nucleoside Transporter; JNK; chemical stress; chemotherapeutic drugs

\section{Introduction}

The Equilibrative Nucleoside Transporters (ENTs) are a Na+-independent class of nucleoside transporters (SLC29) responsible for the uptake of a large number of nucleosides and nucleoside analogs [1]. Among the four members identified (ENT1-4) [1], ENT1 and ENT2 are the best-characterized.

ENT1 is the most abundant and widely distributed plasma membrane nucleoside transporter in human cells that mediates cellular entry of nucleoside-derived antineoplastic drugs such as gemcitabine, cytarabine, and fludarabine [2;3;4]. Deficiency in ENT1 confers

\footnotetext{
(C) 2010 Elsevier Inc. All rights reserved.

Corresponding Author: Andrea V. Leisewitz, Hematology-Oncology Department, School of Medicine, Pontificia Universidad Catolica de Chile, Santiago, Chile, Phone number: (56-2) 3543092, Fax Number: (919) 966 5640, aleisewi@ med.puc.cl.

This is a PDF file of an unedited manuscript that has been accepted for publication. As a service to our customers we are providing this early version of the manuscript. The manuscript will undergo copyediting, typesetting, and review of the resulting proof before it is published in its final citable form. Please note that during the production process errors may be discovered which could affect the content, and all legal disclaimers that apply to the journal pertain.
} 
development of drug resistance in many in vitro models of hematological [5] and solid tumors $[6 ; 7 ; 8]$. On the other hand, high levels of hENT1 represent a positive predictive factor of response to gemcitabine in patients with advanced pancreatic cancer [9], resected disease [10] and metastatic lung disease [7]. These observations make ENTs an important target for study to improve anticancer therapy and drug effectiveness, however little is known about the regulation mechanism of ENT1 expression or activity.

It was previously shown that hypoxia-activated transcription factor, HIF1 $\alpha$ can negatively regulate hENT1 expression [11]. In fact, heterogeneously distributed hypoxic areas are a characteristic property of locally advanced breast cancer and may become resistant to some forms of chemotherapy [12]. On the other hand, it has been reported that inflammatory cytokines can downregulate several transporters (including ENT1) as a result of expression changes $[13 ; 14]$, however the mechanism is not yet understood.

Importantly, the MAP kinases JNKs and p38 are preferentially activated by a variety of cell stresses including proinflammatory cytokines [15] and chemotherapeutic drugs such as gemcitabine, taxol, cisplatin or transplatin [16;17]. This suggests that JNK activation may be a common response to chemotherapy. Earlier gene array analysis experiments demonstrated a reduction in ENT1 expression in 3T3 cells expressing MKK7 [18], a kinase involved in JNK activation [19]. Collectively these observations strongly support the idea that stressactivated signaling pathways are involved in the regulation of nucleoside transport and may contribute to the development of drug resistance.

Using a murine model of chronic myelogenous leukemia we show that JNK-cJun signaling pathway activated by chemical stress negatively regulates mENT1 expression and activity. We also identified a novel and functional c-Jun binding site in the mouse promoter. Finally, our results suggest that the activation of JNK in response to chemotherapeutic nucleoside analogs could contribute to the development of resistance to these or other nucleosidederived drugs.

\section{Materials and Methods \\ Cell culture and reagents}

32Dp185 leukemic cells [20] were grown in RPMI 1640 and HEK 293 cells were grown in DMEM (Invitrogen, Carlsbad, CA, USA) supplemented with 10\% heat inactivated Fetal Bovine Serum and 100 units $/ \mathrm{ml}$ penicillin and $100 \mathrm{mg} / \mathrm{ml}$ streptomycin. Cells were maintained in the presence $5 \% \mathrm{CO}_{2}$ at $37^{\circ} \mathrm{C}$. Uridine- $\left[5,6-{ }^{3} \mathrm{H}\right](35-60 \mathrm{Ci} / \mathrm{mmol})$ and $\left[{ }^{3} \mathrm{H}\right]-$ NBMPR (40Ci/mmol) were purchased from Moravek Biochemicals and Radiochemicals (Brea, CA., USA). Anisomycin, SP600125 and SB220025 were obtained from Calbiochem (La Jolla, California). NBMPR (Nitrobenzylmercaptopurine Riboside, 6-[(40 nitrobenzyl)thio]-9-(b-D-ribofuranosyl)purine), $\beta$-actin and FLAG antibodies were from Sigma-Chemical Co., (St Louis, MO, USA). Antibodies against phospho-cJun (Ser73), phospho-JNK, cJun and JNK were from Cell Signaling Technology (Beverly, MA). cJun and cJun S63/73A expression vectors were obtained from Dr. Michael Birrer (NCI, Rockville, Maryland), MKK7 constructs were obtained from Dr. Lynn E. Heasley (University of Colorado Health Sciences Center, Denver, Colorado, USA) and mENT1 promoter constructs were obtained from Dr. Doo-Sup Choi (Ernesto Gallo Clinic and Research Center and Department of Neurology, University of California, San Francisco, CA, USA).

\section{$\left[{ }^{3} \mathrm{H}\right]$-Uridine uptake assay}

The assay was performed as described previously [21][22]. Briefly, after treatments $3 \times 10^{5}$ cells were washed and suspended in sodium free buffer. After pre-incubation with $1 \mu \mathrm{M}$ 
NBMPR or vehicle (DMSO) for $15 \mathrm{~min}$, uptake assays were started adding equal volume of transport buffer containing $2 \mu \mathrm{M}$ cold uridine, $\left[{ }^{3} \mathrm{H}\right]$-uridine $4 \mu \mathrm{Ci} / \mathrm{ml}$ plus NBMPR or DMSO. Time course of uptake under this condition was performed to determine linearity (not shown). Uptake was stopped after 5 minutes followed by three rapid washes with ice-cold transport buffer containing $1 \mathrm{mM}$ unlabelled uridine. The cell pellets were lysed and centrifuged at $10000 \mathrm{rpm}$ for $10 \mathrm{~min}$ at $4^{\circ} \mathrm{C}$, the supernatant was used to measure radioactivity incorporated. ENT1-dependent uptake was calculated as the difference between total transport (ENT1+ENT2) and transport in the presence of $1 \mu \mathrm{M}$ NBMPR (ENT2). To rule out efflux of the labelled uridine during washes, we performed as a control an assay on a $200 \mu 1$ layer of $84 \%$ silicone $16 \%$ mineral oil. The uptake was stopped by centrifugation of the cells through the oil layer followed by lysis of the cell pellet [23]. No differences were detected between the two methods (not shown). Hypoxanthine uptake (ENT2 activity) was performed in the presence or absence of $1 \mu \mathrm{M}$ NBMPR to confirm ENT1 but not ENT2 inhibition (not shown).

\section{$\left[{ }^{3} \mathrm{H}\right]-N B M P R$ binding assay}

After treatments, $3 \times 10^{5}$ cells were washed 3 times in PBS $1 \mathrm{X}$ and labeled with $25 \mathrm{nM} \mathrm{[}{ }^{3} \mathrm{H}$ ]NBMPR in the presence or absence of $20 \mu \mathrm{M}$ unlabelled NBMPR for $60 \mathrm{~min}$ at room temperature to attain steady-state binding. Cells were washed 3 times in ice-cold 1X PBS

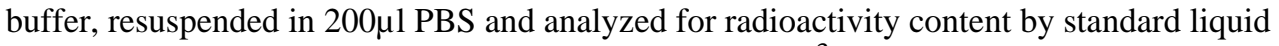
scintillation-counting technique. Non-specific binding of $\left[{ }^{3} \mathrm{H}\right]-\mathrm{NBMPR}$ was defined as that which remained cell-associated in the presence of $20 \mu \mathrm{M}$ unlabelled NBMPR. Specific binding was defined as total binding minus non-specific binding.

\section{Protein extraction and Western blot}

Cells were washed twice in ice cold PBS and lysed with lysis buffer and protease inhibitors (20mM Tris $\mathrm{pH} 7.5,1 \%$ triton, $10 \%$ glycerol, $137 \mathrm{mM} \mathrm{NaCl}$ and $2 \mathrm{mM}$ EDTA, $250 \mu \mathrm{M}$ PMSF, $5 \mu \mathrm{g} / \mathrm{ml}$ Leupeptin, $200 \mu \mathrm{M} \mathrm{NaVO}_{4}$ and $10 \mathrm{nM}$ Microcystin) for $20 \mathrm{~min}$, followed by $12000 \mathrm{rpm}$ for $10 \mathrm{~min}$ at $4^{\circ} \mathrm{C}$ centrifugation. Protein concentration of the supernatant was measured using BCA Protein Assay Kit (Pierce, Rockford, IL, USA). Fifty $\mu$ g proteins were used for inmunoblotting. Membranes were developed using ECL reagents (Amersham Biosciences, UK).

\section{Promoter activity assays}

$1 \times 10^{5}$ HEK 293 cells/well were plated in a 24 -well plate, $24 \mathrm{~h}$ before transfection. $0.5 \mu \mathrm{g}$ of pGL3 mENT1 promoter constructs/well were used, co-transfected with $0.1 \mu \mathrm{g}$ pCMV- $\beta$-Gal vector for internal normalization and $0.3 \mu \mathrm{g}$ of expression vectors when indicated. Lipofectamine (Invitrogen, Carlsbad, CA, USA) was used for cell transfection according to the manufacturer's instructions. Promoter activity was measured $24 \mathrm{~h}$ after transfection using HiLite kit (Perkin Elmer, Boston, MA, USA) and Mammalian $\beta g a l$ assay kit (Pierce, Rockford, IL, USA)

\section{DNA binding assay}

HEK293 cells were transfected with expression vectors for cJun or cJun Ser(63/73)Ala and nuclear extracts were obtained as described previously [24]. Briefly, cells were washed twice with ice cold PBS and resuspended in 400 $\mu 1$ Buffer A (10mM HEPES pH 7.9, 1.5mM $\mathrm{MgCl}_{2}, 10 \mathrm{mM} \mathrm{KCl}, 0.5 \mathrm{mM}$ DTT and protease inhibitor cocktail). After $10 \mathrm{~min}$ on ice cells were centrifuged at $13000 \mathrm{rpm}$ for $4 \mathrm{~min}$ and the supernatant was discarded. Nuclear pellets were resuspended in 50 $\mu 1$ Buffer B (20mM HEPES pH 7.9, $20 \%$ glycerol, $420 \mathrm{mM} \mathrm{NaCl}$, $0.2 \mathrm{mM}$ EDTA, $1.5 \mathrm{mM} \mathrm{MgCl}_{2}, 10 \mathrm{mM} \mathrm{KCl}, 0.5 \mathrm{mM}$ DTT and protease cocktail inhibitor) and after $10 \mathrm{~min}$ on ice pellets were centrifuged at $13000 \mathrm{rpm}$ for $6 \mathrm{~min}$. Protein 
concentration was determined from the supernatants. $100 \mu \mathrm{g}$ of nuclear extract protein were incubated for $1 \mathrm{~h}$ at RT with $1 \mu \mathrm{g}$ biotinylated double stranded oligonucleotide, $10 \mu 1$ streptavidin conjugated beads (Sigma-Chemical Co., St Louis, MO, USA) in 1X binding buffer (10mM TrisHCl pH 7.5, 50mM NaCl, $0.5 \mathrm{mM}$ DTT, $0.5 \mathrm{mM}$ EDTA, $1 \mathrm{mM} \mathrm{MgCl} 2,4 \%$ glycerol and $0.5 \mathrm{mg} / \mathrm{ml}$ poly ( $\mathrm{dI}-\mathrm{dC}$ ) in a final volume of $200 \mu \mathrm{l}$. The beads were washed 3 times with $1 \mathrm{X}$ PBS and 2X loading buffer was added.

\section{Quantitative RT-PCR}

Total RNA was extracted using Trizol (Invitrogen, Carlsbad, CA, USA) according the manufacturer's instructions. $2 \mu \mathrm{g}$ RNA was used for cDNA synthesis using SuperScriptII reverse transcriptase (Invitrogen) according manufacturer's protocol. Expression level for mENT1 was quantified by real-time PCR (7500 Fast Real-Time PCR System, Applied Biosystems; Foster City, CA) according to the manufacturer's instructions. The PCR reaction mixture contained $900 \mathrm{nM}$ each of the sense primer (5'-

ATGGCAAGGGCTCAATGG-3') and antisense primer (5'TGGAGTAAGCGGGCATCAGT-3') for mENT1 or 900nM each of the sense primer (5'TGAAGCAGGCATCTGAGGG-3') and antisense primer (5'CGAAGGTGGAAGAGTGGGAG-3') for mGAPDH. 100ng cDNA and SYBR Green PCR master mix (Applied Biosystems; Foster City, CA) was also added to the reaction mixture. After an initial 10 minute incubation at $95^{\circ} \mathrm{C}$, cDNA was amplified using increasing cycles of $95^{\circ} \mathrm{C}$ for 15 seconds and $60^{\circ} \mathrm{C}$ for 1 minute. Transcript levels and fold change in mRNA between treatments was determined as previously described [25].

No changes in GAPDH levels were detected under the experimental conditions indicated (not shown).

\section{Results}

\section{Anisomycin treatment down-regulates ENT1 activity}

Using a murine model of Bcr-Abl leukemia, 32Dp185 cells [20], we investigated the relationship between cell stres s and ENT1 activity regulation. Cells were incubated with anisomycin, a fungal derivative that blocks translation, induces cell stress and activates of JNK and p38 MAP kinases [26]. Anisomycin treatment resulted in a time-dependent reduction of mENT1-dependent uridine uptake of $\approx 50 \%$ that correlated with the activation of JNK and the phosphorylation of the transcription factor activated by JNK, cJun (Fig. 1A and 1B). Similarly, treatment with $30 \mathrm{ng} / \mathrm{ml}$ or $50 \mathrm{ng} / \mathrm{ml}$ anisomycin (3h), downregulated ENT1-dependent uridine uptake by $50 \%$, whereas preincubation with a potent JNK inhibitor, SP600125, but not the p38 MAPK inhibitor, SB220025, (not shown), partially blocked this effect and JNK and cJun phosphorylation (Fig. 1C, 1D). This data indicated that JNK activation was necessary for ENT1 downregulation and that the reduction in ENT1 was not a nonspecific effect of anisomycin.

Cell surface ENT1 protein was measured by radiolabeling with the high-affinity and selective, non-transportable ENT1 inhibitor, ${ }^{3}[\mathrm{H}]-\mathrm{NBMPR}$ [27]. Anisomycin treatment $(50 \mathrm{ng} / \mathrm{ml})$ decreased ${ }^{3}[\mathrm{H}]$-NBMPR binding by $\approx 50 \%$ indicating loss of mENT1 protein from the cell surface (Fig. 2A). The effect persisted after $6 \mathrm{~h}$ of anisomycin treatment, and correlated with the downregulation of mENT1-dependent activity suggesting a significant decrease in mENT1 on the cell surface.

The c-Jun $\mathrm{NH}_{2}$-terminal kinase (JNK) pathway represents a major physiological mechanism of regulation of cJun, a component of the AP-1 transcription factor [28]. Mouse embryo fibroblasts (MEFs) that lack expression of both ubiquitously expressed $j n k$ genes exhibit markedly reduced expression or phosphorylation of cJun, on the $\mathrm{NH}_{2}$-terminal sites (Ser-63 
and Ser-73). The time-dependent JNK and c-jun phosphorylation observed in 32Dp185 cells after anisomycin treatment (Fig. 1B) correlated with diminished mENT1 mRNA content as analyzed by qRT-PCR (Fig. 2B). Moreover, preincubation with SP600125 inhibited the effects of anisomycin on mENT1 mRNA down-regulation (Fig. 2C), confirming that JNK signaling affected the transcriptional regulation of mENT1.

Ara-C and chemotherapeutic drugs such as Gemcitabine ( $2^{\prime}, 2^{\prime}$-difluorodeoxycytidine) induce JNK activation in different cell types, [29;30] and are widely used for the treatment of leukemias and other cancers. In 32Dp185 cells we observed JNK phosphorylation followed by a decrease in ENT1 mRNA by $20 \%$ and $40 \%$ after AraC and Gemcitabine treatment respectively and a decrease in ENT1-dependent uridine uptake after $6 \mathrm{~h}$ treatment (data not shown). These observations suggest that the JNK signaling pathway is involved in the decrease of ENT1.

\section{JNK activation down regulates mENT1 promoter activity}

The sequence of murine ENT1 (mENT1) promoter has been described [31]. To investigate the JNK-dependent mENT1 expression downregulation, we transfected HEK293 cells with luciferase-coupled mENT1 promoter constructs [31] (Fig. 3A). HEK293 cells showed similar JNK activation and cJun phosphorylation after anisomycin treatments (Fig. 3B right panel). After $6 \mathrm{~h}$ anisomycin treatments, the luciferase activity and $\beta$-galactosidase activities were measured. As shown in Fig. 3B, anisomycin decreased mENT1 promoter activity in three of the four promoter constructs tested, pLuc-2121, pLuc-1479 and pLuc-652. By contrast, pretreatment with the JNK selective inhibitor, SP600125 prevented the anisomycin-dependent down-regulation of mENT1 promoter activity (Fig. 3C).

In order to confirm the involvement of JNK in mENT1 promoter regulation, HEK293 cells were cotransfected with mENT1 promoter constructs and an MKK7 expression vector and the amount of luciferase activity measured. These results indicated that MKK7 overexpression, downregulated pLuc-2121 and pLuc-1479 activities, but not pLuc-994 nor pLuc-652 (Fig. 3D) suggesting that the region contained in pLuc-1479 and pLuc-2121 contained the promoter element that responded to MKK7 overexpression. As expected, the transcription factor c-Jun was highly phosphorylated under these conditions (Fig. 3D right panel).

\section{Identification of a functional AP-1 binding site in the mouse ENT1 promoter}

Analysis of the mENT1 promoter using Signal Scan (http://www-bimas.cit.nih.gov/molbio/signal/), Transcription Element Search Software, TESS (http://www.cbil.upenn.edu/cgi-bin/tess/tess) and MatInspector Promoter Analysis Tool (Genomatix, www.genomatix.de) suggested that there was an AP-1 binding site at -1196 in a region of the mENT1 promoter contained in the pLuc-2121 and pLuc-1479 fragments. This site was not detected previously [31] and is located close to two SP1 and a CREB binding sites (Fig. 4A). To examine if cJun was directly involved in mENT1 promoter activity regulation, we overexpressed c-Jun, as well as the c-Jun mutant Ser63/73Ala protein. cJun overexpression but not cJun Ser63/73Ala mutant produced a significant downregulation of $\mathrm{p} 2121$ promoter activity, strongly supporting the previous results (Fig. 4B). Under these conditions, and as expected, c-Jun but not c-Jun Ser63/73Ala was highly phosphorylated (Fig. 4C).

We next performed DNA binding assays to examine for c-Jun binding to the mENT1 promoter AP-1 site. A biotin end-labeled probe that contained the putative AP-1 binding site in the mENT1 promoter was incubated with nuclear extracts of cells overexpressing cJun or the Ser/Ala mutant. We observed that c-Jun, but not the c-Jun Ser/Ala mutant bound to the 
mENT1 AP-1 site (Fig. 4D). Incubation with a non-specific, non-biotinylated probe was unable to compete for this binding demonstrating that c-Jun binding was specific (Fig. 4D). These results confirmed that the AP-1 binding site identified in the mENT1 promoter is functional and that cJun is able to bind to it.

\section{Discussion}

ENT-mediated transport of nucleoside analogs can be the rate limiting step for drug-induced cytotoxicity [4]. The results presented here define an important role for the stress kinase JNK in the negative regulation of mENT1-dependent transport under drug-induced stress conditions. We show that JNK activation downregulates mENT1 expression and that the transcription factor cJun is able to bind to the mENT1 promoter. Supporting this idea we observed that chemotherapeutic drugs that activate JNK downregulate mENT1 activity suggesting that stress-induced JNK activation may contribute to the development of nucleoside analogs resistance through this mechanism.

Our data is consistent with a rapid decrease in mENT1 expression. The reduction in mENT1 mRNA and promoter activity were followed by a decrease in mENT1-dependent activity and NBMPR binding, demonstrating that loss of mENT1 activity was strongly correlated to loss of mENT1 on the cell surface. However, we cannot rule out the possibility of posttranslational modifications of the mENT1 protein, such as phosphorylation that may also influence mENT1 internalization or subcellular localization.

The MAPK family of kinases responds to extracellular stimuli. ERKs are strongly activated by mitogens, while the JNKs and p38 are preferentially activated by a variety of cell stresses [32]. JNK phosphorylates cJun on two serine residues, Ser 63/73 and many of the cellular effects of JNK activation are mediated through activation of the AP-1 complex [33] positively modulating the expression of several genes. In contrast, our results suggest that JNK activation, cJun phosphorylation and promoter binding negatively regulate mENT1 expression. Consistent with previous observations, [18] expression of the active MKK7 reduced the mENT1 promoter activity.

Downregulation of ENT1 has been also observed in response to inflammatory agents [14] that induce JNK activation, i.e. Nitric oxide (NO) [34;35]. Moreover, NO reduced hENT1 promoter activity in HUVEC cells possibly by a transcription factor, able to bind the distal region of hENT1 promoter [35]. Interestingly, our in silico analysis of the human ENT1 promoter suggests at least two putative AP-1 binding sites in the distal region (unpublished observations), suggesting that ENT1 regulation by cJun might be a common feature.

The results presented here provide potentially important mechanism contributing to nucleoside analog drug resistance. Our results suggest that cell stress induced by chemotherapeutic agents may downregulate ENT1 expression through a JNK-dependent mechanism. In support of this, we observed that two different nucleoside analogs inhibited ENT1-dependent activity and expression, although weaker than thus observed with anisomycin that paralleled JNK activation. In summary, the present study describes a mechanism by which chemical stress-induced JNK activation decreases ENT1 expression in a c-Jun-dependent manner potentially leading to the development of drug resistance.

\section{Research Highlights}

- $\quad$ Stress activated kinases downregulate the expression of several transporters

- $\quad$ JNK activation and cJun phosphorylation downregulate mENT1 expression 
- $\quad$ mENT1 promoter contains an AP1 binding site and cJun is able to bind mENT1 promoter

JNK signaling pathway regulates mENT1 expression

\section{Acknowledgments}

Grant Support: NIH Grant RO1-GM069976 to Lee M. Graves.

\section{References}

1. Baldwin SA, Beal PR, Yao SY, King AE, Cass CE, Young JD. The equilibrative nucleoside transporter family, SLC29. Pflugers Arch. 2004; 447:735-743. [PubMed: 12838422]

2. Giovannetti E, Mey V, Nannizzi S, Pasqualetti G, Del Tacca M, Danesi R. Pharmacogenetics of anticancer drug sensitivity in pancreatic cancer. Mol Cancer Ther. 2006; 5:1387-1395. [PubMed: 16818496]

3. Takagaki K, Katsuma S, Kaminishi Y, Horio T, Nakagawa S, Tanaka T, Ohgi T, Yano J. Geneexpression profiling reveals down-regulation of equilibrative nucleoside transporter 1 (ENT1) in Ara-C-resistant CCRF-CEM-derived cells. J Biochem. 2004; 136:733-740. [PubMed: 15632314]

4. Pastor-Anglada M, Molina-Arcas M, Casado FJ, Bellosillo B, Colomer D, Gil J. Nucleoside transporters in chronic lymphocytic leukaemia. Leukemia. 2004; 18:385-393. [PubMed: 14737075]

5. Cai J, Damaraju VL, Groulx N, Mowles D, Peng Y, Robins MJ, Cass CE, Gros P. Two distinct molecular mechanisms underlying cytarabine resistance in human leukemic cells. Cancer Res. 2008; 68:2349-2357. [PubMed: 18381442]

6. Mackey JR, Mani RS, Selner M, Mowles D, Young JD, Belt JA, Crawford CR, Cass CE. Functional nucleoside transporters are required for gemcitabine influx and manifestation of toxicity in cancer cell lines. Cancer Res. 1998; 58:4349-4357. [PubMed: 9766663]

7. Seve P, Dumontet C. Chemoresistance in non-small cell lung cancer. Curr Med Chem Anticancer Agents. 2005; 5:73-88. [PubMed: 15720263]

8. Cano-Soldado P, Molina-Arcas M, Alguero B, Larrayoz I, Lostao MP, Grandas A, Casado FJ, Pastor-Anglada M. Compensatory effects of the human nucleoside transporters on the response to nucleoside-derived drugs in breast cancer MCF7 cells. Biochem Pharmacol. 2008; 75:639-648. [PubMed: 18053967]

9. Spratlin J, Sangha R, Glubrecht D, Dabbagh L, Young JD, Dumontet C, Cass C, Lai R, Mackey JR. The absence of human equilibrative nucleoside transporter 1 is associated with reduced survival in patients with gemcitabine-treated pancreas adenocarcinoma. Clin Cancer Res. 2004; 10:6956-6961. [PubMed: 15501974]

10. Farrell JJ, Elsaleh H, Garcia M, Lai R, Ammar A, Regine WF, Abrams R, Benson AB, Macdonald J, Cass CE, Dicker AP, Mackey JR. Human equilibrative nucleoside transporter 1 levels predict response to gemcitabine in patients with pancreatic cancer. Gastroenterology. 2009; 136:187-195. [PubMed: 18992248]

11. Eltzschig HK, Abdulla P, Hoffman E, Hamilton KE, Daniels D, Schonfeld C, Loffler M, Reyes G, Duszenko M, Karhausen J, Robinson A, Westerman KA, Coe IR, Colgan SP. HIF-1-dependent repression of equilibrative nucleoside transporter (ENT) in hypoxia. J Exp Med. 2005; 202:14931505. [PubMed: 16330813]

12. Mackey JR, Jennings LL, Clarke ML, Santos CL, Dabbagh L, Vsianska M, Koski SL, Coupland RW, Baldwin SA, Young JD, Cass CE. Immunohistochemical variation of human equilibrative nucleoside transporter 1 protein in primary breast cancers. Clin Cancer Res. 2002; 8:110-116. [PubMed: 11801546]

13. Petrovic V, Teng S, Piquette-Miller M. Regulation of drug transporters: during infection and inflammation. Mol Interv. 2007; 7:99-111. [PubMed: 17468390]

14. Soler C, Felipe A, Casado FJ, Celada A, Pastor-Anglada M. Nitric oxide regulates nucleoside transport in activated B lymphocytes. J Leukoc Biol. 2000; 67:345-349. [PubMed: 10733094] 
15. Verheij M, Bose R, Lin XH, Yao B, Jarvis WD, Grant S, Birrer MJ, Szabo E, Zon LI, Kyriakis JM, Haimovitz-Friedman A, Fuks Z, Kolesnick RN. Requirement for ceramide-initiated SAPK/JNK signalling in stress-induced apoptosis. Nature. 1996; 380:75-79. [PubMed: 8598911]

16. MacKeigan JP, Collins TS, Ting JP. MEK inhibition enhances paclitaxel-induced tumor apoptosis. J Biol Chem. 2000; 275:38953-38956. [PubMed: 11038347]

17. Levresse V, Marek L, Blumberg D, Heasley LE. Regulation of platinum-compound cytotoxicity by the c-Jun N-terminal kinase and c-Jun signaling pathway in small-cell lung cancer cells. Mol Pharmacol. 2002; 62:689-697. [PubMed: 12181446]

18. Han SY, Kim SH, Heasley LE. Differential gene regulation by specific gain-of-function JNK1 proteins expressed in Swiss 3T3 fibroblasts. J Biol Chem. 2002; 277:47167-47174. [PubMed: 12354774]

19. Nishina H, Nakagawa K, Azuma N, Katada T. Activation mechanism and physiological roles of stress-activated protein kinase/c-Jun NH2-terminal kinase in mammalian cells. J Biol Regul Homeost Agents. 2003; 17:295-302. [PubMed: 15065757]

20. Cortez D, Stoica G, Pierce JH, Pendergast AM. The BCR-ABL tyrosine kinase inhibits apoptosis by activating a Ras-dependent signaling pathway. Oncogene. 1996; 13:2589-2594. [PubMed: 9000132]

21. Leisewitz AV, Zimmerman EI, Jones SZ, Yang J, Graves LM. Imatinib-resistant CML cells have low ENT activity but maintain sensitivity to gemcitabine. Nucleosides Nucleotides Nucleic Acids. 2008; 27:779-786. [PubMed: 18600540]

22. Huang M, Wang Y, Cogut SB, Mitchell BS, Graves LM. Inhibition of nucleoside transport by protein kinase inhibitors. J Pharmacol Exp Ther. 2003; 304:753-760. [PubMed: 12538831]

23. Bone DB, Hammond JR. Nucleoside and nucleobase transporters of primary human cardiac microvascular endothelial cells: Characterization of a novel nucleobase transporter. Am J Physiol Heart Circ Physiol. 2007

24. Fuenzalida KM, Aguilera MC, Piderit DG, Ramos PC, Contador D, Quinones V, Rigotti A, Bronfman FC, Bronfman M. Peroxisome proliferator-activated receptor gamma is a novel target of the nerve growth factor signaling pathway in PC12 cells. J Biol Chem. 2005; 280:9604-9609. [PubMed: 15632188]

25. Livak KJ, Schmittgen TD. Analysis of relative gene expression data using real-time quantitative PCR and the 2(-Delta Delta C(T)) Method. Methods. 2001; 25:402-408. [PubMed: 11846609]

26. Barbacid M, Vazquez D. (3H)anisomycin binding to eukaryotic ribosomes. J Mol Biol. 1974; 84:603-623. [PubMed: 4601392]

27. Bone DB, Robillard KR, Stolk M, Hammond JR. Differential regulation of mouse equilibrative nucleoside transporter 1 (mENT1) splice variants by protein kinase CK2. Mol Membr Biol. 2007; 24:294-303. [PubMed: 17520485]

28. Davis RJ. Signal transduction by the JNK group of MAP kinases. Cell. 2000; 103:239-252. [PubMed: 11057897]

29. Stadheim TA, Saluta GR, Kucera GL. Role of c-Jun N-terminal kinase/p38 stress signaling in 1beta-D-arabinofuranosylcytosine-induced apoptosis. Biochem Pharmacol. 2000; 59:407-418. [PubMed: 10644049]

30. Teraishi F, Zhang L, Guo W, Dong F, Davis JJ, Lin A, Fang B. Activation of c-Jun NH2-terminal kinase is required for gemcitabine's cytotoxic effect in human lung cancer H1299 cells. FEBS Lett. 2005; 579:6681-6687. [PubMed: 16307741]

31. Choi DS, Handa M, Young H, Gordon AS, Diamond I, Messing RO. Genomic organization and expression of the mouse equilibrative, nitrobenzylthioinosine-sensitive nucleoside transporter 1 (ENT1) gene. Biochem Biophys Res Commun. 2000; 277:200-208. [PubMed: 11027664]

32. Johnson GL, Nakamura K. The c-jun kinase/stress-activated pathway: regulation, function and role in human disease. Biochim Biophys Acta. 2007; 1773:1341-1348. [PubMed: 17306896]

33. Dunn C, Wiltshire C, MacLaren A, Gillespie DA. Molecular mechanism and biological functions of c-Jun N-terminal kinase signalling via the c-Jun transcription factor. Cell Signal. 2002; 14:585593. [PubMed: 11955951]

34. Chung HT, Pae HO, Choi BM, Billiar TR, Kim YM. Nitric oxide as a bioregulator of apoptosis. Biochem Biophys Res Commun. 2001; 282:1075-1079. [PubMed: 11302723] 
35. Farias M, San Martin R, Puebla C, Pearson JD, Casado JF, Pastor-Anglada M, Casanello P, Sobrevia L. Nitric oxide reduces adenosine transporter ENT1 gene (SLC29A1) promoter activity in human fetal endothelium from gestational diabetes. J Cell Physiol. 2006; 208:451-460. [PubMed: 16688763] 

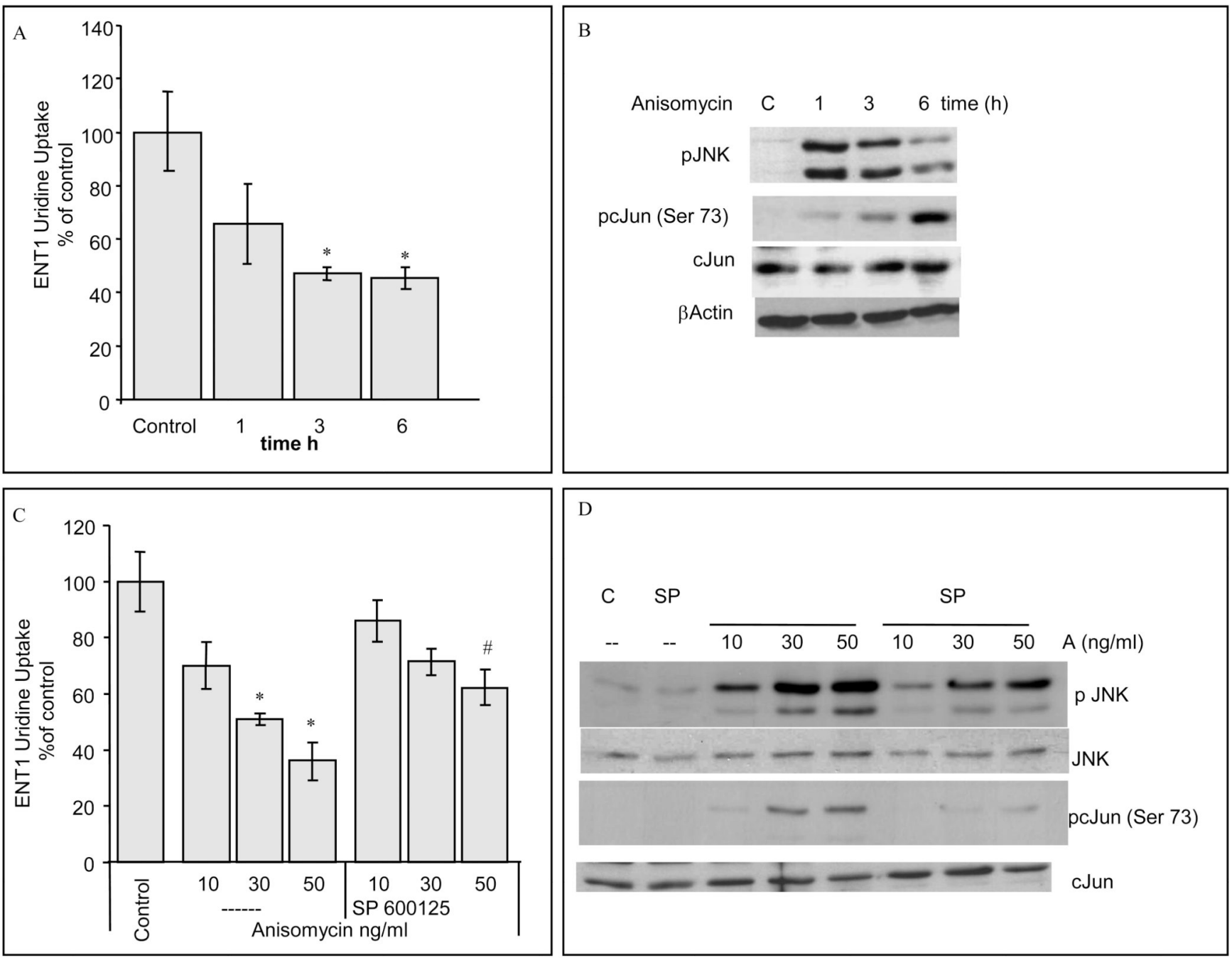

Figure 1. Anisomycin treatment decreases ENT1 activity

32Dp185 were incubated with 50ng/ml anisomycin for the times indicated. The values shown in the graphs represent means \pm S.D. of data (A) ENT1-dependent ${ }^{3}[\mathrm{H}]$-Uridine uptake. $(n=6, * p<0.05)$. (B) Immunoblot analysis for pJNK, pc-Jun (Ser73), total c-Jun and $\beta$-actin. Shown is a representative experiment of three separate experiments. (C) 32Dp185 ENT1-dependent ${ }^{3}[\mathrm{H}]$-Uridine uptake after $3 \mathrm{~h}$ of 10,30 and $50 \mathrm{ng} / \mathrm{ml}$ anisomycin treatments, pretreated with or without $10 \mu \mathrm{M}$ SP600125 JNK inhibitor for $1 \mathrm{~h}(\mathrm{n}=3, * \mathrm{p}<0.05$ statistical significance compared to the corresponding SP600125+Anisomycin value, \#p<0.05 statistical significance compared to control value). (D) Cells were treated with 10, 30 and $50 \mathrm{ng} / \mathrm{ml}$ anisomycin (A) for $3 \mathrm{~h}$ pretreated with or without $10 \mu \mathrm{M}$ SP600125 (SP) JNK inhibitor for 1h. Immunoblot analysis for pJNK, pc-Jun (Ser73), total c-Jun and total JNK. Shown is an experiment representative of three separate experiments. 

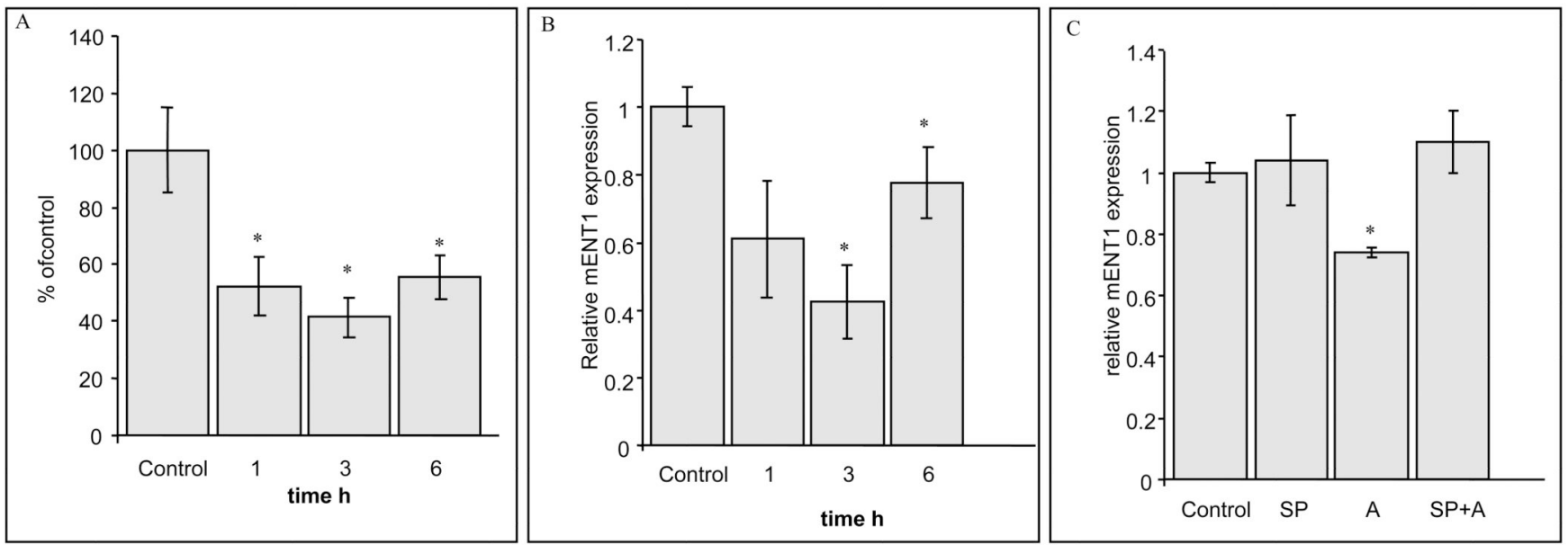

Figure 2. Anisomycin down-regulates ${ }^{3}[\mathrm{H}]$-NBMPR binding and ENT1 expression

32Dp185 cells were treated with $50 \mathrm{ng} / \mathrm{ml}$ anisomycin for the times indicated. The values shown in the graphs represent means \pm S.D. (A) ${ }^{3} \mathrm{H}-\mathrm{NBMPR}$ binding. $\left(\mathrm{n}=3,{ }^{*} \mathrm{p}<0.05\right)$. (B) Real Time RT-PCR was performed to quantify the relative change in mENT1 transcript $\left(\mathrm{n}=3,{ }^{*} \mathrm{p}<0.05\right)$. (C) Real Time RT-PCR was performed to quantify the relative change in mENT1 transcript after $50 \mathrm{ng} / \mathrm{ml}$ anisomycin (A) treatments for $3 \mathrm{~h}$ pretreated with or without $10 \mu \mathrm{M}$ SP600125 (SP) JNK inhibitor for $1 \mathrm{~h}\left(\mathrm{n}=3,{ }^{*} \mathrm{p}<0.05\right)$. 

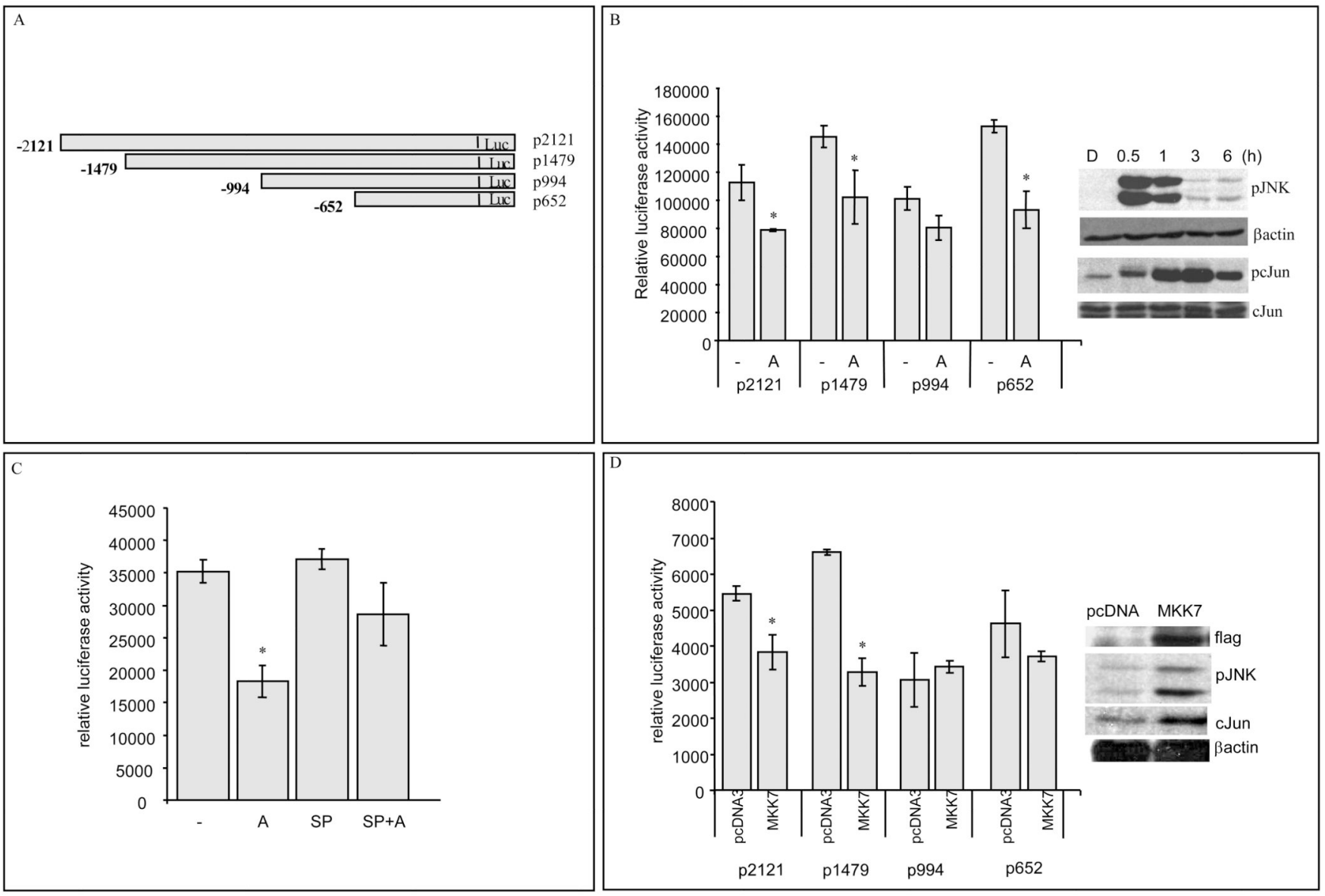

Figure 3. JNK activation decreases mENT1 promoter activity

Data points represent sample means \pm S.D. of data $(\mathbf{A})$ mENT1 promoter picture $(\mathbf{B})$

Relative promoter activity in anisomycin treated cells. HEK293 cells transfected with different mENT1 promoter fragments were treated with anisomycin (A) $50 \mathrm{ng} / \mathrm{ml}$ for $6 \mathrm{~h}$. (Representative experiment, $\left.\mathrm{n}=6,{ }^{*} \mathrm{p}<0.05\right)$.). Right panel: Immunoblot analysis for $\mathrm{pJNK}$, pc-Jun (Ser73), total c-Jun and $\beta$-actin from HEK293 cells treated with anisomycin 50ng/ml for the times indicated. (C) mENT1 pLuc-2121 promoter fragment activity in HEK293 cells treated with anisomycin (A) 50ng/ml, 10 $\mathrm{MM}$ SP600125 (SP) or combination of SP and anisomycin $(\mathrm{SP}+\mathrm{A})$ for $6 \mathrm{~h}$. (Representative experiment, $\left.\mathrm{n}=6,{ }^{*} \mathrm{p}<0.05\right)$. (D) Promoter activity in flag-MKK7 expressing HEK293 cells cotransfected with different mENT1 luciferase-coupled promoter fragments. (Representative experiment, $\mathrm{n}=3$, ${ }^{*} \mathrm{p}<0.05$ ). Right panel: Immunoblot analysis for flag-MKK7, pJNK, total c-Jun and $\beta$-actin from HEK293 cells transfected with pcDNA3 or MKK7 expression vector. 

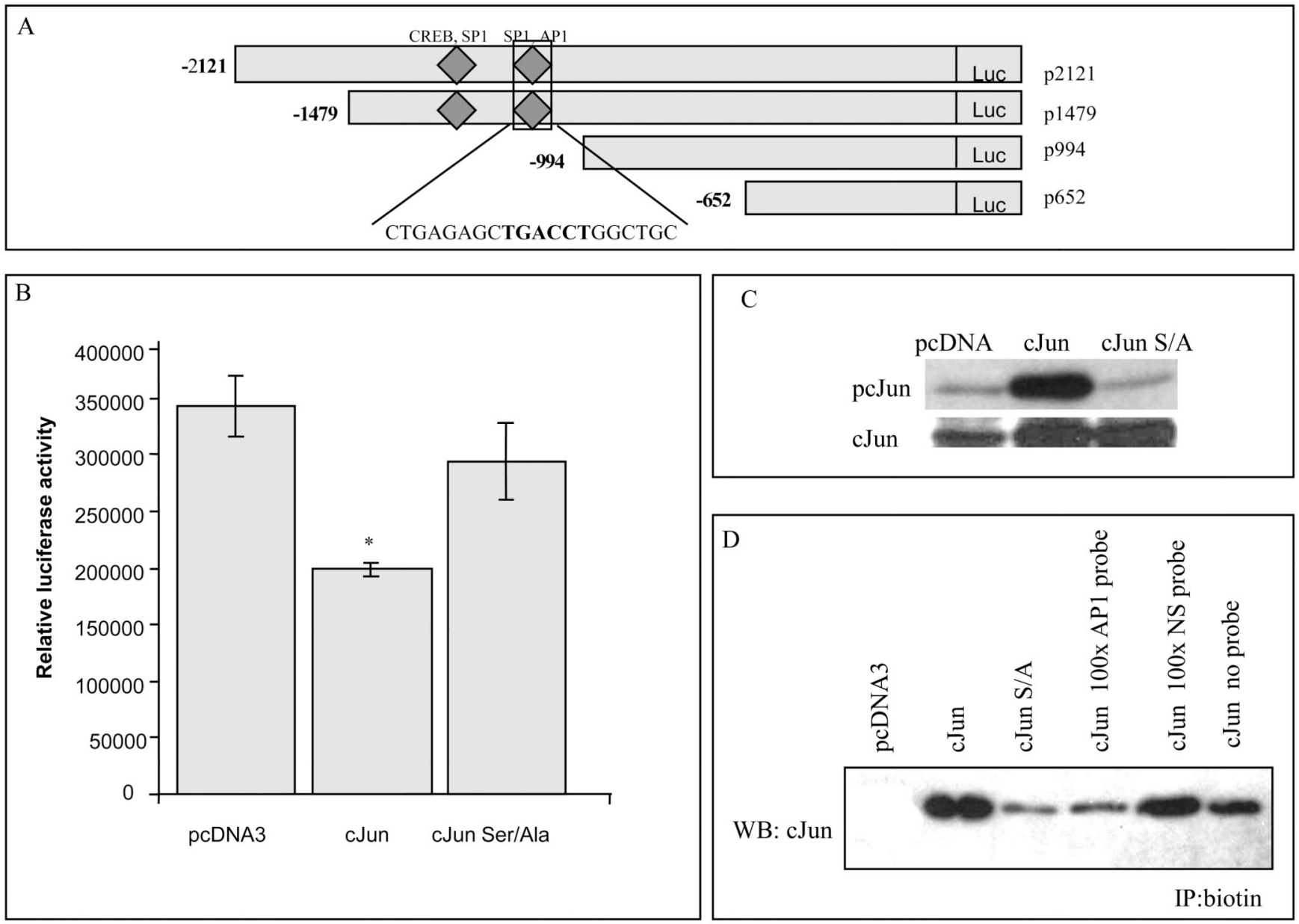

Figure 4. c-Jun overexpression reduces mENT1 promoter activity and binds to a novel AP1 binding site in the mENT1 promoter

(A) Graphic representation of the mENT1 promoter fragments that contain the identified AP-1 binding site. Sequence is presented. (B) Promoter activity in c-Jun expressing cells. 293 cells were cotransfected with pLuc-2121 promoter fragment of the luciferase coupled mENT1 promoter vector and pcDNA3, c-Jun expression vector or the mutant c-Jun Ser63/73Ala. The values shown in the graph represent means \pm S.D. of data from a representative experiment $(n=3, * p<0.05)$. (C) Immunoblot analysis of $50 \mu \mathrm{g}$ protein from 293 cells transfected with pcDNA3, c-Jun or c-Jun Ser63/73Ala expression vector for pc-Jun (Ser73) and total c-Jun presence. (D) DNA binding assay. $1 \mu \mathrm{g}$ of biotinylated AP-1 containing double stranded probes were incubated with nuclear extracts from 293 cells transfected with pcDNA3, c-Jun or c-Jun Ser63/73Ala expression vector. For specificity assay $1 \mu \mathrm{g}$ of biotinylated AP-1 containing double stranded probe was incubated with nuclear extracts from HEK293 cells transfected with c-Jun and coincubated with 100 times excess of non biotinylated AP-1 containing probe or 100 times excess of a non-biotinylated non-specific (NS) probe. 